\title{
A Quantitative Approach for Valuating Architectural Qualities
}

\author{
Ulf Nordwall* and Thomas Olofsson
}

Department of Applied Physics and Electronics, Umeå University, SE-901 87 Umeå, Sweden

\begin{abstract}
Architectural qualities is often valuated based on a describable nature with a more personal interpretation, such as living space, size of ground plot, the number of sanitation rooms, or standard points according to the property taxation.Models with values of a more measurable qualitative nature, such monetary parameters, are less used. Within other research areas, for example the environmental and economic field, there are examples of well used qualitative models. One example is the Contingent Valuation (CV) model. It can be used to measure values in terms of willingness to pay on a hypothetic market. In this paper we introduce adirect quantitative approach for evaluating architectural qualities based on the theory of CV. The architectural qualities investigated are: the patina and mellowness of building components, usage flexibility within the apartment, and properties and characteristics of the surroundings.

The method has been applied on a smaller case-study of 150 people living in cooperative and rented flats at Ålidhem, Ålidbacken and Östermalm in Umeå, Sweden. The case study was used merely to demonstrate and evaluate the methodology. The study indicated that the introduced three architectural values could be investigated with the used CV approach. It was found that the tenants had a measureable willingness to pay for those qualities. This supports a notion that valuations of architectural qualities are not entirely subjective and dependent on the individuals. Consequently the study supports the proposal to use qualitative measures to grade and compare such qualities.
\end{abstract}

Keywords: Architectural quality, Management, Cooperative flat, Rented flat, Quantitative method, Monetary terms.

\section{INTRODUCTION}

In business management it is important to identify and measure how costumers value the offered product qualities. For the housing real estate management sector the tenants are the customers and the product is an offer of a living space. There are some studies in the literature reporting on living space qualities from a tenant customer perspective. One reported aspect of living quality for the tenants is the relations between neighbours;another is to the real-estate manager. It is found that an increased tenants tendency to take responsibility of the accommodation can be measured if the relation to the housing company is good, which can have positive effects on how long the tenants are staying as well [1]. Other aspects of qualities, reported by several studies, are issues subsequent of social housing companies in Western Europe are not being able to develop and renew enough [2,3,4]. One example is that the management has been ineffective and the housing companies have been focused on technology and building production, and have overlooked customer and service issues. The focus of the housing companies in technology and building production has nevertheless more and more developed into an interest in management and customer issues. One example is customer proximate organisation, which is about how the housing company to a greater extent adjust their service in customer relations. Those services can include adapted opening hours, social media, and meetings between for example manager and tenants in various forums. The increased awareness of customer

*Address correspondence to this author at the Department of Applied Physics and Electronics, Umeå University, SE-901 87 Umeå, Sweden;

Tel: + 46-733374802; Email: ulf.nordwall@peab.se and service issues show that focus is moving from the buildings to the people, which is something the tenant value [1]. A tone-sided focus on the production phase can become very expensive in the management phase [5]. Naming and defining the significance of the qualities of the building, and modify these qualities to a management perspective, that are resubmitted to the production stage, will contribute to invest in long-term and smart solutions in an early stage [6].

Besides the service issues there are several examples of building construction related qualities that are more or less possible to influence. For example, to a certain extent, it is possible to influence the architecture of the building, especially in the stages of planning and production. On the contrary, the situation of the building site is more or less definite and difficult to influence. However, it is possible to choose how to dispose and utilize the characteristics of the surroundings. Based on that perspective of building construction qualities three architectural qualities were selected to be examined on an earlier qualitative pre-study [7]. The used methodology was grounded theory. The investigated qualities were the patina and mellowness of building components, usage flexibility within the apartment, and properties and characteristics of the surroundings. The study showed that care was important. It is about care of the houses, the surroundings, the material of the houses, and of the design of the houses, care of the tenants and of the homes they have chosen to make their own.

Besides the study of qualitative investigations of architectural values, introduced above, there are surprising few evaluations of architectural values based on quantitative terms. Generally, the architectural qualities reported in the literature are of a describable nature, such as living space, 
size of ground plot, the number of sanitation rooms, or standard points according to the property taxation. Other kinds of architectural quality measures, like quality measurements for architectural qualities, are rarely investigated [8].

Searching into the literature of real estate research there are examples of attempts to evaluate architectural qualities in more absolute measurable terms. Based on a larges survey of estate professionals complemented by a survey of occupants [9] a conclusion was that it appeared that there were a relationship between quality and return. That analysis was based on a combination of a statistical and a hierarchical approach. In another example, where the architectural quality in an urban economic perspective was investigated, the methodology was based on a hedonic prize index with easy collected housing characteristics for 131 row houses in a Victorian neighbourhood in the United States [10]. That study gave evidence that the residential architecture matters in the marketplace and that the architectural features appear to be more valuable if one row housedifferentiate from its immediate neighbours.

What distinguishes quantitative studies of architectural qualities is that they often are related to a personal interpretation. The qualities can be difficult to define in in more absolute quantitative terms, such as price. This problem is not unique for the field of architecture. Within other research areas there are examples where quantitative models have been developed to meet that problem. A good example is the research of environmental resources and economy.In the literature one can find examples in evaluation research. Different techniques have been developed to evaluate environmental values. These techniques can be split into two main groups, direct and indirect methods. A direct method is based on interviews / questionnaires, e.g. about the willingness to pay. An indirect method uses the existing connection between the quality and the market.

The indirect methods are based on the actual behaviour of the individuals. A disadvantage is that one can not underestimate the existence of values. An example of an indirect method is the discharge of pollutants into a lake that affect water quality reducing the catch of fish.

The direct methods provide an opportunity to estimate the total value of a quality orresource. This method attempts to directly estimate a value, which usually takes place through structured interviews or questionnaires.

In the environmental economy approaches of direct and indirect methods has been proposed. Some of these have been based on the willingness to pay. That measure wasintroducedin 1967 by the well-known economist, John Krutilla. He presented the idea that a person may be willing to pay in order to save a certain resource despite the fact that the person him- or herself would not consider to visit or utilize it [11]. This willingness to pay is motivated by the concern for present and future generations. Adam Smith begins his book Theory of Moral Sentiments [12] with a reflection on altruism. Smith considered that it obviously existed some basic features in the human nature that made us care for people's wellbeing. He found there had to be a sense of sympathy.
A direct method was used in a study to reduce gasoline vapours, by Katz \& Sterner [13]. An increase in petrol prices as payment instruments was investigated in terms of willingness to pay. Another example is found in a study by Boman\&Bostedtabout preserving a Swedish wolf population [14].A nationwide sample was investigated based on the willingness to pay.An additonal example of use of a direct method can be found in a study by Bishop and Heberlein [15]. They introduced the idea of giving the individual a cost, a bid, of air quality problems, to consider rather than having to state the maximum willingness to pay directly in the interview.

To evaluate qualities that do not have a market Harrison \&Rubinfeld [16] used an indirect hedonic price method to examine how the prices of houses in the Boston area varied according to different background factors such as crime, distance from the city centre, the municipal tax rate, number of pupils per teacher, population composition and concentration of nitrous gases. The method is based on a choice situation and an assumption that the individuals had adequate information.

In economic research one can use, hypothetical markets when experiment markets are not convenient. The establishment of hypothetical markets to immediately bring out the willingness to pay for an environmental product or service has been used in that field. By means of interviews or surveys, a change in the supply of an environmental product is described to a usually random selection of people. Then questions are asked about the individuals' willingness to pay for a realisation of the change. This method is usually called Contingent Valuation (CV). The name is due to wanting to emphasize that the willingness to pay is contingent to the described scenario.

The scope of this work is to introduce and demonstrate aCV-approach of a direct method for investigating architectural qualities in quantitative terms.An objective is to use that methodto investigate three architectural qualities of a building which had been the object of an earlier qualitative study [7]; the patina and mellowness of building components, usage flexibility within the apartment, and properties and characteristics of the surroundings, qualities. A small case study is introduced, where the method has been used on residential tenants in Umeå, Sweden The outcome of the approach is to evaluate useful measures, in a real estate management perspective.

\section{METHOD}

In this study we have applied a direct approach ofa CV method to try out its adaptation in the field of architecture. The ambition is to try and develop a method to investigate the willingness to pay regarding architectural qualities. The methodology can be divided into three phases.

\subsection{Phase 1 - Development}

In this first phase the question formulation is defined. Which architectural qualities will be evaluated and how will they be described to the responders? Additionally, it is necessary to decide the level of the statistical selection of the respondents and the general nature of the results. Will the selection be local or consist of alarger geographical range? 
Since, in this study we are primarily introducing a method for measuring architectural qualities the statistical representation was less prioritized. We chose to investigate three residential areas in Umeå: Ålidbacken, Ålidhem and Östermalm.

A crucial issue in the study is what kind of information is relevant. What is enough information of the architectural qualities? Therefore we have limited the questions the responders could relate to.

\subsection{Phase 2 - Construction}

The construction of aquestionnairewas based on a quite thorough phase with various kinds of tests in order to find clear formulations of how the architectural qualities are related to the accommodation. A pilot study with a smaller group of people was used to test and comment the first drafts of the questionnaire.

The questionnaire was finally introduced with a presentation and information. The questionnaire is split into four sections consisting of a number of portion questions. The first nine questionnaire questions consist of fixed answering alternatives and concern gender, age, occupation, education of the tenants and the present form of housing, how long they have lived in the present apartment, previous form of housing, the size of the apartment, and which form of housing they prefer.

The following four questions consist of the open questions about the willingness to pay, in concern to the present rent and how much more in rent the responder is willing to pay for the three qualities; the patina and mellowness of building components; the usage flexibility within the apartment; the properties and characteristics of the surroundings. The question about the monthly rent has partly been used to relate to the potential willingness to pay in monetary terms. But the questionnaire also partly identifies other probable connections and links. In the subsequent analysis section we have calculated the willingness to pay in relation to the current rent, and investigated it in the perspective to other data collected in this questionnaire.

In the questionnaire there was also a possibility for the tenants to give their own suggestions on what they consider to be important architectural qualities contributing to a good housing. Thus, here there were no fixed answering alternatives they had to fill in with their own words and opinions.

The last and fourth section consists of two fixed answering alternatives where the tenants identify if the patina and mellowness of building components, usage flexibility within the apartment, the properties and characteristics of the surroundings or other architectural quality had significance in the choice of their housing, partly when they moved from their previous apartment, and partly when they moved to their current apartment.

The advantage with questionnaires is that they are relatively inexpensive and easy to manage. On the other hand one have less control over the responder's comprehension of the contents of the questionnaire. It is more difficult for the responder to discuss ambiguities.

\subsection{Phase 3 - Analysis and Report}

The answering frequencycan be a first indication of statistical significance. In this study the answering frequency was $75 \%$, which was found appropriate.

The questionnaire answers were analysed in several manners. In a first step the frequency of the questionnaire answers was compiled, regarding statements of facts as well as quality assessments. The responders' own comments about architectural qualities was compiled, compared and analysed.

The estimation of average and median willingness to pay is simple if one, as in this study, uses the open question about the willingness to pay. In a traditional CV study one do not know the exact willingness to pay since definite costs are used instead of open willingness to pay.

The result from this estimation can then be used to calculate the average willingness to pay for each architectural quality. The model was based on how much more tenants are willing to pay in rent when thehouses are ready for occupation. The method also gives some possibilities to manage several variables at the same time, and track connections, if there are any.

The wishes and demands on the design of housings are locally conditioned. The supply of housingvaries between different districtse.g. based on population structure. Parallel studies of housing markets in a metropolitan area and a medium-sized town with a comparatively balanced housing market can give clearer and more general results regarding the significance of specific architectural qualities for the willingness to pay. In this perceptive the methodology could be applicable to revile information of the willingness to pay for certain qualities.

\section{CASE STUDY}

The developed methodology has been applied on a number of flats in Umeå, Sweden, in a case study. The studiedobjects are partly rented flats at ̊lidbacken and Ålidhem, managed by $\mathrm{AB}$ Bostaden, and partly cooperative flats atÖstermalm, managed by Riksbyggen. Considering the whole housing stock in Umeå, the selected categories and the conditions or the tenantsare not proposed to be fully representative in any manner, not locally and not nationally representative. The study should merely be regarded as a case study. In this section a short presentation of the three housing areas Åldbacken, Ålidhem and Östermalm, are introduced.

\section{1. Ålidbacken}

Alidbacken (Fig. 1) was built from the middle of the 1950 s till the middle of the 1960s, approximately 3 kilometres from the city centre. The site is located close to the two large places of work in Umeå, Umeå University and the University Hospital of Northern Sweden. With its simple buildings, its location close by to the expanding hospital, and its proximity to the city centre, Ålidbacken became the area in Umeå where a more extensive renovation for housing construction became possible. 


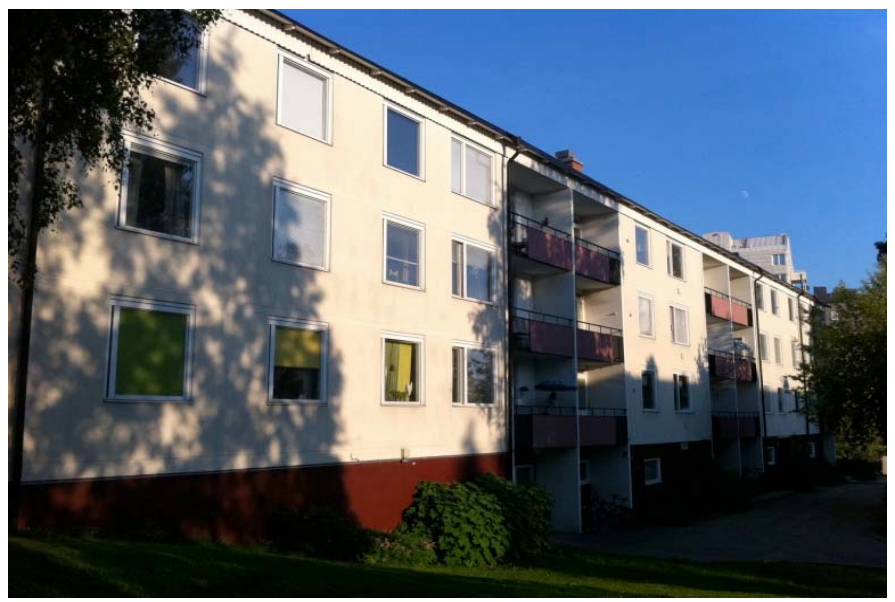

Fig. (1). Ålidbacken bright construction details from one of the building's facades.

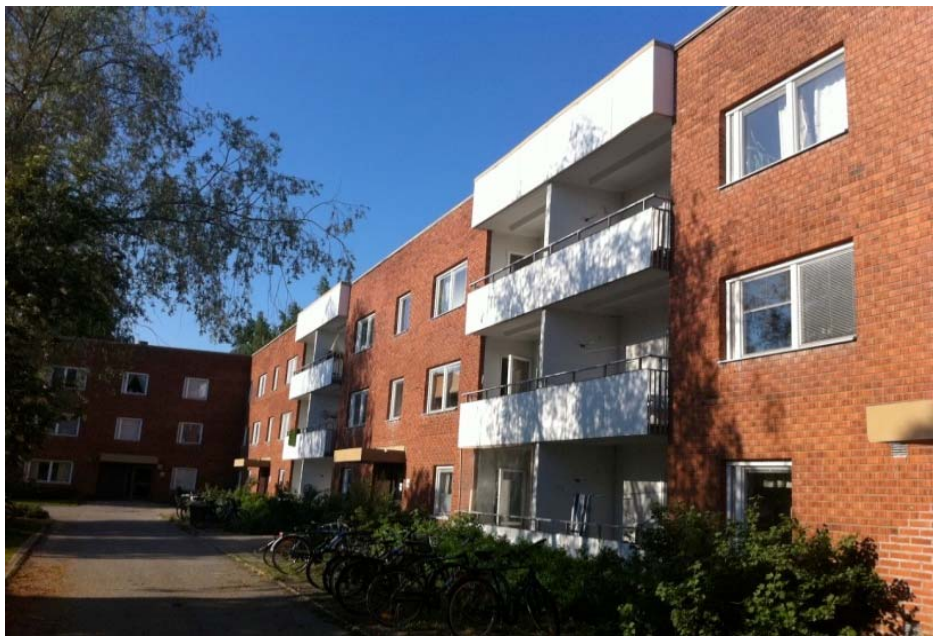

Fig. (2). Ålidhem facade with beautiful original red bricks from one of the Quarter at Ålidhem.

\section{2 Ålidhem}

Ålidhem (Fig. 2) is situated approximately 3 kilometres from the city centre. It is a district in Umeå that was built between 1966 and 1973, as a part of the Swedish national social housing program, The Million Programme.

As Ålidbacken, Ålidhem was planned on the peat soil for an area of small houses. The establishment of the university and the extension of the regional hospital resulted in other policies for the constructions in the district. Now it was a matter of, in a short period of time, meet the increasing demand on housing, not least for students, and employers at the university and the hospital.

The buildings mainly consist of two- up to four-storey houses of red brick. During the 1990s however, several houses have acquired additional storeys, and have been supplemented with tower blocks. In the trade, Ålidhem is described as a typical and well thought-out Swedish example of the rational urban construction of the 1960s.

\section{3. Östermalm}

Östermalm (Fig. 3) is a district in Umeå, close to the Umeå river and approximately 1,5 kilometres from the city centre. Until the 1940s it had the characteristics of the buildings of the outskirts, with small houses and yards. Today none of the original houses and yards from the old Östermalmis left. An important aspiration with the architecture on Östermalm, built in the 1980 s, was to accomplish an intimate and pleasant environment with small squares, alleys, and green areas between the houses.

The ranges of colours from the surrounding wooden houses have been brought into the area's colour scheme of the area, and the pedestrian streets in the area are intended to be a continuation of the structure if inner city of Umeå. With the two 9-storey houses and intermediate houses along Östermalmsgatan it is indicated where the inner city begins.

\section{THE RESULT OF THE MODEL}

In this section, first we introduce the results of the conducted survey, as a case study, followed by some general remarks.

\subsection{Result of the Case Study}

The proposed approach was dispatch in a survey to 150 households. The dispatch was made during March 2010. The selection of the tenants in the various areas is made to obtain 


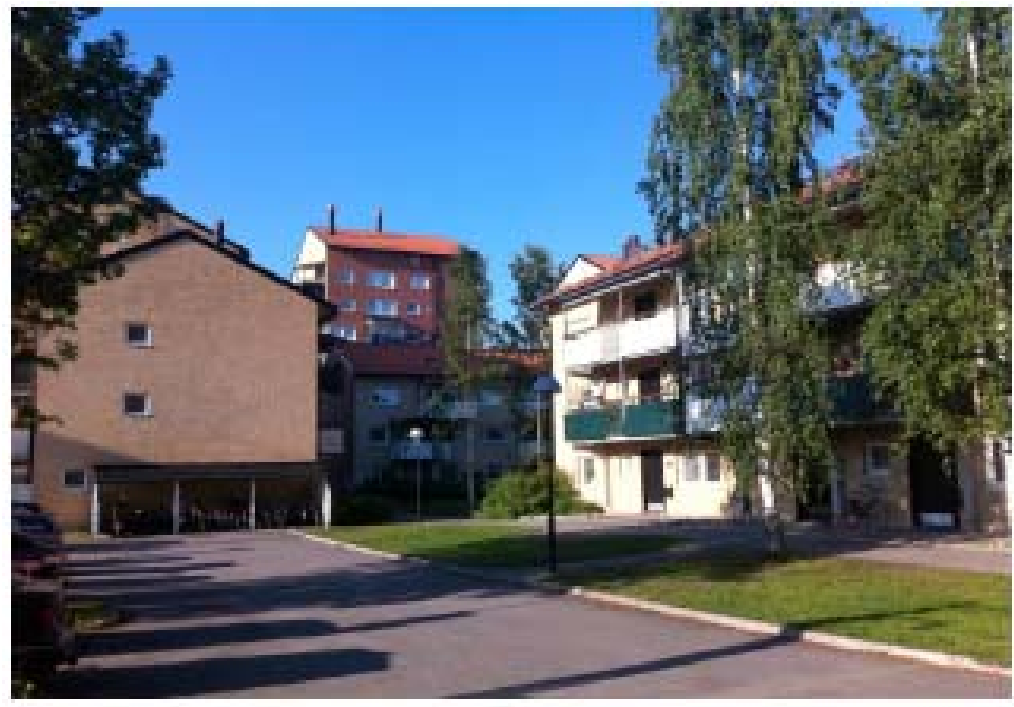

Fig. (3). Östermalm interesting mix of different sizes of houses creates beautiful yards.

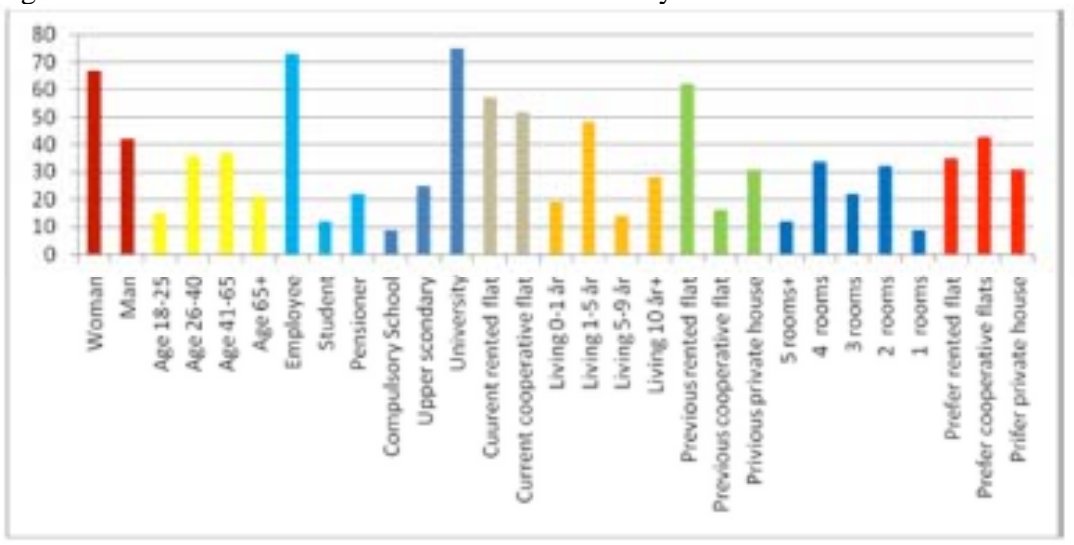

Fig. (4). Distribution of the respondents in categories.

a broad range of housing categories, on the basis of gender, age, and social conditions, that is to say, a random dispatch but certain steering towards different sizes on flats. The distribution of the responders in the various categories is presented in Fig. (4).

As it appears, some groups are represented by only a few respondents. The basis for assessment of these groups' willingness to pay is therefore not statistically significant. In the dispatch an addressed envelope was enclosed. In each area, the falloff of the survey answers was $25 \%$. This falloff was somewhat bigger before a reminder was sent out. The falloff on account of incomplete answered surveys was two. In only 12 occasions were the questions left unanswered where the tenant should fill in his/her own ideas about what are important architectural qualities. The frequency of answers should therefore be considered acceptable. Additionally due to falloff of answers in the survey,some of the category groups do not sum up to $100 \%$.

The measure in terms of the tenants' willingness to pay for the various qualities was compiled by regulating the stated surplus value in the rent with the current rent. The average value for this willingness to pay as a ratio of the rent for all responders is presented in Fig. (5).
The tenants' own merged average value of the willingness to pay for the patina and mellowness of building components $(3,0 \%)$, usage flexibility within the apartment $(4,0 \%)$, and the properties and characteristics of the surroundings $(2,8 \%)$.

This measurement of the willingness to pay for each architectural quality may then be studied for all of the studied groups of tenants. To facilitate a relative comparison the regulated surplus value has been related to how much all of the responders have stated as surplus value. The result is that for most of the categories the willingness to pay diverges relatively little. For some of the categories, the divergence is however larger. A selection of the most significant results are presented in Table 1a and Table $\mathbf{1 b}$.

In this particular study it appears that women in general have a larger willingness to pay than men. The group with 41-65 year of age have an overall positive willingness to pay, while the oldest group have a more negative willingness to pay. Those who live in rented flats have a larger willingness to pay than those who live in cooperative flats. The ones who live in the bigger flats have a negative willingness to pay, while the ones who live in the smaller flats have a positive willingness to pay. Those who prefer a rented flat also have negative willingness to pay. The largest willingness to 


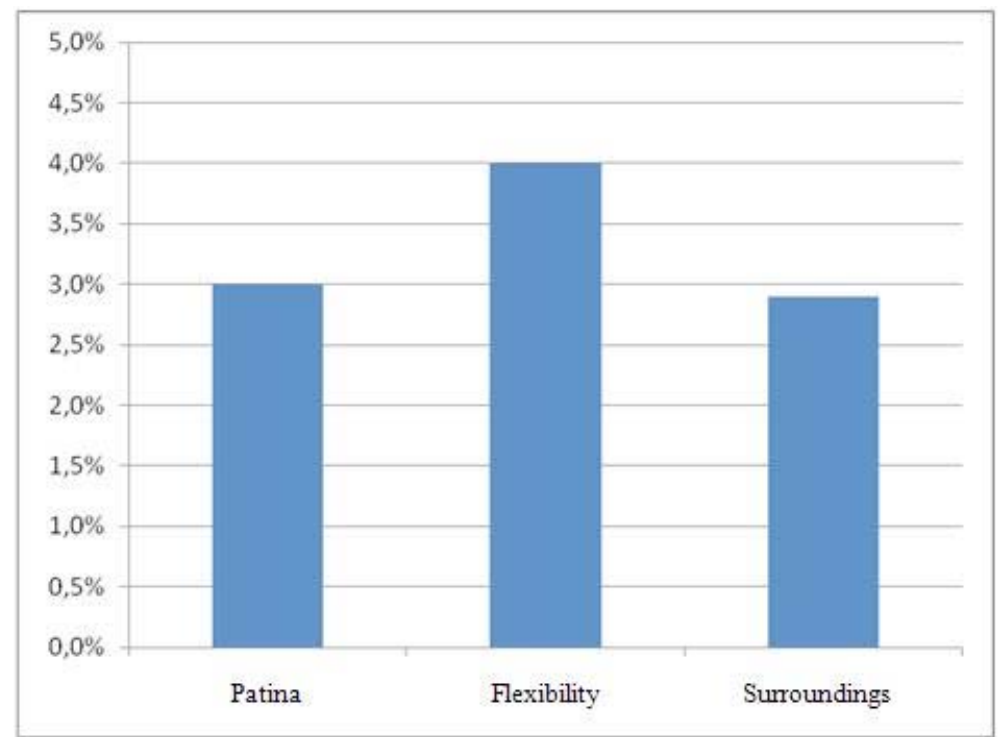

Fig. (5). Average values of the tenants' willingness to pay as a ratio of the rent for the three architectural qualities.

Table 1a. Results for Housing Categories Based on Gender, Age and Number of Room (r) in the Apartment, with Significant DIVERGENCE in the Willingness to Pay in Relation to the Average Value of the Survey Group

\begin{tabular}{|c|c|c|c|c|c|c|c|c|c|}
\hline & Woman & Man & Age 41-65 & Age 65+ & $5 \mathrm{r}+$ & $4 r$ & $3 \mathbf{r}$ & $2 r$ & $1 \mathbf{r}$ \\
\hline Patina & $20 \%$ & $-30 \%$ & $40 \%$ & $-40 \%$ & $-37 \%$ & $-17 \%$ & $-37 \%$ & $40 \%$ & $67 \%$ \\
\hline Flexibility & $7 \%$ & $-10 \%$ & $23 \%$ & $-45 \%$ & $-20 \%$ & $5 \%$ & $-10 \%$ & $10 \%$ & $10 \%$ \\
\hline Surroundings & $10 \%$ & $-10 \%$ & $45 \%$ & $-66 \%$ & $-24 \%$ & $3 \%$ & $-34 \%$ & $41 \%$ & $-38 \%$ \\
\hline
\end{tabular}

Table 1b. Results for Housing Categories Based on Previous and Preferred Living as Well as Qualities, with Significant Divergence in the Willingness to Pay in Relation to the Average Value of the Survey Group

\begin{tabular}{|c|c|c|c|c|c|}
\hline & Previous Rented Flat & Previous Cooperative flat & Prefer Rented Flat & Patina for Choice & Patina for Moving \\
\hline Patina & $-17 \%$ & $17 \%$ & $-43 \%$ & $113 \%$ & $147 \%$ \\
\hline Flexibility & $-15 \%$ & $18 \%$ & $-33 \%$ & $58 \%$ & $125 \%$ \\
\hline Surroundings & $-17 \%$ & $21 \%$ & $-28 \%$ & $114 \%$ & $107 \%$ \\
\hline
\end{tabular}

pay belongs to those who stated that the materials were crucial for the decision of the current housing, and to those who stated the material as the reason for moving from the previous housing. Also those who stated the outdoor environment as a reason for moving from the previous housing, show a larger willingness to pay.

In a section of the questionnaire there was an option for the tenants to register their own suggestions about what they consider to be important architectural qualities contributing to a pleasant accommodation. Thus, in this section there were no fixed answering alternatives, but the tenants filled in their own words and ideas. Three qualities predominated; neighbours, location and sound. The percentage of the tenants' relation to these qualities is presented in Fig. (6).
The tenants' own comments on other qualities and architectural qualities important for the wellbeing and accommodation. The tenants also stated proper material that endure aging, planning with openness and plenty of daylight as important for their wellbeing, and also details and design of windows, doors, skirting boards and cupboard interiors. The developed model tested on the three locations in Umeå gave a result that shows in what way the tested groups value the three architectural qualities. Thus the survey answers proposed to represent the whole local area and not give any statistically significant results regarding correspondence between the tenants' assessment of architectural qualities in a management perspective and the willingness to pay. Despite 


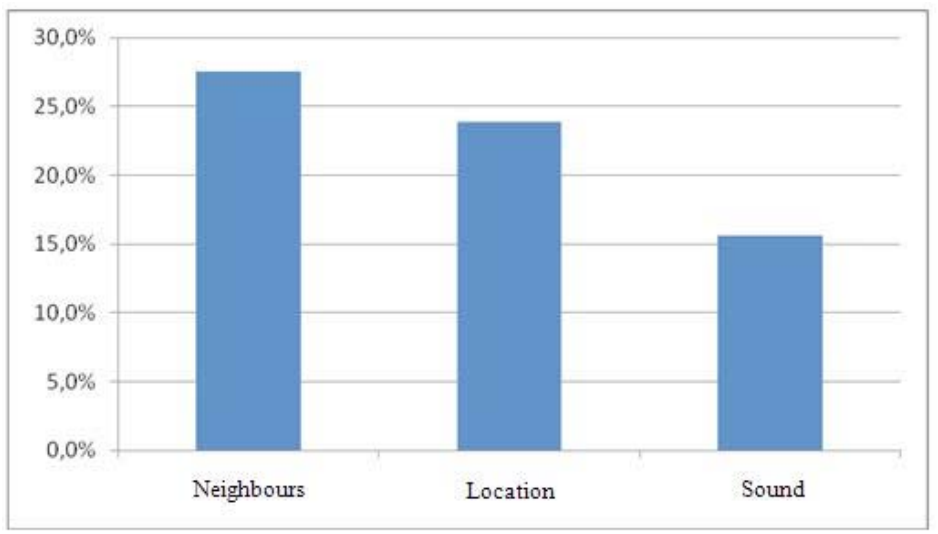

Fig. (6). Distributionsof the percentage thewhat the responding tenants assessed important qualities in their accommodation, besides the proposed three architectural qualities based on an open question in the questionnaire.

this, the answers may indicate the tenants' assessment criteria.

\subsection{General Remarks of the Results}

The model is developed to value architectural qualities in quantitative terms, where a investigated value is based onhow much more the tenants are willing to pay, in relation to present rent, when the houses are ready for accommodation.The method also gives some opportunities to manage several variables at once and trace possible connections.

The issue of valuation of architectural qualities in quantitative terms, in this study willingness to pay per month in relation to monthly rent, makes the concept applicable for the real estate management context. In all business it is important to identify and measure how costumers appreciate the offered product qualities. For the real estate management sector the tenants are the customers and the product is an offer is of a living space. A measure of the qualities in monetary term can be proposed as useful for real estate management in general as well as for real estate development.

From the case study it was indicated that certain criteria can be found, as drivers on tenants to go through the effort of moving. A very large portion, 99 of 109 responders, $90 \%$, think that it is architectural qualities such as usage flexibility within the apartment, the properties and characteristics of the surroundings or the patina and mellowness of building components that contributed to the choice of moving from the previous to current housing.

Shortly summarized, this study revealed that also when the tenants themselves could leave their suggestions for qualities, they had pronounced concurrence. In the top-three list, following characteristics were emphasized as significant to the tenants from the case study in Umeå.

- Good relationships with neighbours, totally 30 of 109 $(27,5 \%)$

- Locality of and within the house, totally 26 of $109(23,8$ $\%)$

- Soundproofed houses, totally 17 of $109(15,6 \%)$

Since these three qualities were not included as optional in the questionnaire, in a future application of this survey form, the possibility of an addition to include them could be considered.

The case study gave the picture that the housing choice is somewhat complex. Some of the interviewees, say they had to renounce some architectural qualities for the benefit of other, such as accept inferior planning for the benefit of a nice garden, or accept the lack of spacious storerooms for the benefit of having a balcony, choices made from the basic restriction that there were no housing that could fulfil all wishes in the desired area.

In the case study, it was indicated that the responding tenants emphasize light open rooms, balcony, and quality of handicraft as important qualities. Many tenants have stated that they appreciate housing made of proper material that endure aging, planning with openness and plenty of daylight. Details and design of windows, doors, skirting boards and cupboard interiors are significant.

Thus the case study verifies that there are unanimous understandings about what are important qualities, and that it also exist a willingness to pay for these things. This supports the idea that assessments of architectural qualities are not entirely subjective and related to specific individuals. Based on that it is possible to grade and compare such qualities.

\section{CONCLUSIONS}

In this work we have introduced and tested an approach of a direct quantitative $\mathrm{CV}$ method to measure architectural qualities in monetary terms. The method can be developed further into a tool and create the possibility for house-owners and project developers for an alternative way of viewing what the tenants value as important qualities and architectural qualities.

The method was tested in a case study in Umeå. An interpretation of the result is that the tenants included in the case study consider the architectural qualities usage flexibility within the apartment, the patina and mellowness of building components and properties and characteristics of the surroundings, as significant for the wellbeing, and value and grade these as important.

There are ideas for development of the method and inquiry. Desires and demands on the design of housing are locally conditioned. The supply of housing as well as the 
composition of the population varies between localities. Parallel studies of housing markets in a big city area and in a medium sized city with relatively balanced housing market can give a clearer result and more general conclusions regarding willingness to pay for architectural qualities in a management perspective.

Another kind of research project that would be interesting for the development of theory within architecture research is to develop this model further to combine architectural qualities with, for instance the cost of energy, the geographic location or the supply of service roads, expressed in monetary terms.

There is a significant need for knowledge within the building construction business about what thetenants' request. The method developed and tested in this case study indicates towards many interesting possibilities to further development within that field.

Through developing and combining methods it is possible to support the results in several ways and still have control over the disadvantages each method has. In a study by Merriam [17] it is pointed out that triangulation is a useful method of securing validity and reliability in a qualitativeinquiry.Results of interviews based on architectural qualities with the developed method may improve a support of the interpretation of the statistical analysis and vice versa.

\section{ACKNOWLEDGEMENT}

None declared.

\section{CONFLICT OF INTEREST}

None declared.

\section{REFERENCES}

H. Vestergaard, "Neighbourhood Governance - A Study on Regeneration", in the European Network for Housing Research Conference Housing: Growth and Regeneration, Cambridge, England, July 2004.
[2] P. Malpass, “The Restructuring Of Social Rented Housing In Britain: Demunicipalization And The Rise Of 'Registered Social Landlords"', International Journal of Housing Policy, vol. 1, pp. 1-16, January 2001.

[3] J. Moseley, "Bottom-up 'Village Action Plans': Some Recent Experience in Rural England", Planning Practice \& Research, vol. 17, pp. 387-405, November 2002

[4] R. M. Walker, "How to Abolish Public Housing: Implications and Lessons from Public Management Reform”, Housing Studies, vol. 16, pp. 675-696, September 2001.

[5] A. Kadefors, "Beställar - entreprenörrelationer i byggandet: samarbete, konflikt och social påverkan", PhD-thesis, Chalmers University of Technology, Gothenburg, Sweden, 1997.(In Swedish)

[6] I. Blomberg, L. Hedberg and C. Jensfelt, "Ytterstadssatsningen: en lägesrapport", Stockholm. Gatu- och fastighetskontoret, Stockholm, Sweden, september 1997 (In Swedish)

[7] U. Nordwall, Importance of Architectural Attributes in Facilities Management, In: Atkin, B., Borgbrant, J. and -Josephson, P.-E. Eds. Construction Process Improvement, Wiley: Chichester, GBR, 2008

[8] I-B. Werner, "Spelarkvalitetnågon roll förpriset?: en studieavbostadsrättsköp i Storstockholm", PhD- thesis, The Royal Institute of Technology, Stockholm, Sweden, 2000.(In Swedish)

[9] A. Baum, "Quality and Property Performance", Journal of PropertyValuation and investment, vol. 12, pp. 31-46, January 1990.

[10] J. C. Moorhouse, and M. S. Smith, "The Market for Residential Architecture: 19th Century Row Houses in Boston's South End", Journal of Urban Economics, vol. 35, pp. 267-277, May 1994.

[11] J. V. Krutilla, "Conservation Reconsidered", The American Economic Review, vol. 57, pp. 777-786, September 1967.

[12] The theory of moral sentiments / Adam Smith ; ed. by D.D. Raphael and A.L. Macfie, The Glasgow edition of the works and correspondence of Adam Smith, Oxford : Clarendon P., 1976

[13] K. Katz, and T. Sterner, Värdering av renare luft, Ekonomiska samfundets Tidskrift, vol. 4, pp. 243-256, 1989.(In Swedish)

[14] M. Boman, and G. Bostedt, Valuing the Wolf in Sweden: Are Benefits Contingent upon the Supply? In: Boman, M., Brännlund, R. \&Kriström, B. (Eds.): Topics in Environmental Economics. Kluwer Academic Press, Dordrecht, 1999.

[15] R.C. Bishop, and T. A. Herberlein, "Measuring Values of Extra Market Goods: Are Indirect Measures Biased?", American Journal of Agricutural Economics, vol. 61, pp. 926-930, 1979.

[16] D. Harrison, and D. L. Rubinfel, "Hedonic prices and the demand of clean air", Journal Environmental Economics and Management, vol. 5, pp. 81-102, 1978.

[17] S. Merriam, Fallstudien som forskningsmetodik, Lund: Studentlitteratur, 1994. (In Swedish) 